\title{
Suppression of Neointimal Hyperplasia Following Angioplasty-Induced Vascular Injury in Pigs Infected with Swinepox Virus
}

\author{
Takeshi Shimamura ${ }^{1, \#}$, David Jeng ${ }^{1}$, Alexandra Lucas ${ }^{2}$ and Karim Essani ${ }^{*}, 1$ \\ ${ }^{1}$ Laboratory of Virology, Department of Biological Sciences, Western Michigan University, 1903 West Michigan Ave, \\ 3441 Wood Hall, Kalamazoo, MI 49008-5410, USA \\ ${ }^{2}$ Divisions of Cardiovascular Medicine and Rheumatology, University of Florida, 1600 SW Archer Rd, PO BOX 100277, \\ Gainesville, FL, 32610-0277, USA
}

\begin{abstract}
Many patients suffering from angina pectoris are treated with percutaneous coronary intervention (PCI) and quickly develop angiographic renarrowing, or restenosis, at the site of PCI treatment. Restenosis is thought to arise from the combinatorial activation of thrombotic and inflammatory responses. The inflammatory response responsible for restenosis is also thought to involve the activation of a cascade of serine proteases and its subsequent regulation. Poxviruses are known to possess a variety of immunomodulatory strategies, some of which target serine proteases, cytokines, and chemokines. To this end we evaluated whether systemic species-specific swinepox virus (SPV) infection could induce sufficient host-immune modulation to promote an anti-inflammatory and anti-proliferative effect, thereby preventing restenosis. Two groups of domestic feeder pigs were used - the first group was experimentally infected with SPV $(n=11)$ and the second group served as an uninfected control $(n=5)$. A week after infection, the pigs were anesthetized and percutaneous transluminal coronary angioplasty (PTCA) was performed in the left anterior descending coronary artery using X-ray fluoroscopy to visualize the balloon and record angiograms. Three weeks post infection, the pigs were euthanized and balloon angioplasty injured arteries were harvested and examined. We observed a statistically significant reduction of restenosis in SPV-infected pigs $(\mathrm{p}=0.05)$ compared to control pigs and conclude that systemic swinepox virus infection causes sufficient host immune suppression to significantly reduce restenosis in pigs after balloon angioplasty injury.
\end{abstract}

Keywords: Coronary artery diseases, inflammation, neointimal proliferation, percutaneous transluminal coronary antioplasty, restenosis, swinepox virus.

\section{INTRODUCTION}

Percutaneous coronary intervention (PCI) or balloon angioplasty alone $(\mathrm{POBA}=$ plain old balloon angioplasty) provides relief from angina pectoris in patients with single and multi-vessel coronary artery disease (CAD). Angiographic renarrowing at the site of a previous PCI is known as restenosis and occurs in approximately $30-50 \%$ of patients at 6 months after the procedure [1]. Restenosis after $\mathrm{PCI} / \mathrm{POBA}$ is the major problem limiting long-term efficacy of this procedure. With the use of stents (a bare metal strut) delivered on an angioplasty balloon, the restenosis rate has been successfully lowered by roughly $10 \%$ (20 - 40\% restenosis dependent upon the type of lesion and acuity) when compared to balloon angioplasty alone $[2,3]$. The advent of drug eluting stents (DES) coated with agents that interfere with cellular proliferation (sirolimus or rapamycin and paclitaxel) has further reduced the restenosis

*Address correspondence to this author at the Laboratory of Virology, Department of Biological Sciences, Western Michigan University, 1903 West Michigan Ave, 3441 Wood Hall, Kalamazoo, MI 49008-5410, USA; Tel: 269-387-2661; Fax: 269-387-5609; E-mail: karim.essani@wmich.edu

"Present Address: Department of Molecular Pharmacology and Therapeutics, Oncology Institute, Loyola University Chicago Stritch School of Medicine, 2160 $\mathrm{S}{ }^{\text {st }}$ Ave, Cardinal Bernardin Cancer Center, Maywood, IL 60153, USA rate to $10-15 \%$, but episodes of acute late stent thrombosis have occurred with inadequate anti-platelet therapy or resistance to platelet inhibition. Currently, the DES has become one of the principal treatments for coronary artery stenosis, together with bare metal stents (BMS) both of which carry some risk of in stent restenosis (ISR) and/or sudden thrombosis [4]. Thus while improved, the problem of restenosis and/or thrombosis persists. Acute thrombotic events are postulated to be caused by a lack of adequate reendothelialization, protective cell covering of the metal stent struts embedded in the artery wall as well as inflammatory reactions to the metal and the DES polymer drug coating. Due to the inherent risk of ISR with the use of stents, POBA is used to alleviate ISR thus preventing two layers of stents. Despite the well-documented track record of reducing ISR using these procedures, it is important to continue investigating other means of treatment.

Although the typical restenotic lesion is different from the atherosclerotic plaque in architecture and composition, both restenotic and atherosclerotic plaques contain smooth muscle cells and fibrous tissue, as well as infiltrating inflammatory macrophages and T cells. After vascular injury is induced by PCI/ POBA, the activation of the inflammatory response is followed by intimal smooth muscle cell proliferation and migration, extracellular matrix formation and neointimal hyperplasia [5]. These events are initiated by 
both cellular and clot forming components of the blood, damaged vascular endothelial cells, connective tissue exposed by balloon denudation, and inflammatory cell mediators [6]. A critical stage in the development of restenosis is thought to be the activation of an inflammatory response, including platelet adhesion, platelet aggregation, fibrin (clot) deposition, and leukocyte infiltration [7]. This inflammatory response also involves enzymatic activation of serine protease activity and its subsequent regulation by serine protease inhibitors [8]. One of the serine protease inhibitors, plasminogen inhibitor-1 (PAI-1), has been demonstrated to play a significant role in suppression of intimal hyperplasia in some animal models [9]. PAI-1 knockout mice showed accelerated intimal hyperplasia as observed histologically [10,11]. Similarly, inhibition of plasminogen with traexamic acid reduced smooth muscle cell migration following arterial balloon injury in rats [12]. Coagulation and fibrinolytic enzymes are known to induce monocyte motility, chemotaxis, tissue infiltration, cell proliferation, and apoptosis $[8,10,11,12]$. The search for an agent that prevents restenosis after PCI still represents an important area of biomedical research. Anticoagulants, antiplatelet agents, calcium channel blockers, lipid-lowering agents, steroidal and non-steroidal anti-inflammatory drugs have all been unsuccessful in the prevention of restenosis [7].

Viruses have complicated lifestyles and have been used to develop many tools used in biological research. Lentiviruses, adenoviruses and retroviruses have all been genetically modified to exploit their gene transfer abilities and prevent neointimal hyperplasia in animal models $[13,14]$. Large DNA viruses, especially poxviruses and herpesviruses, have a wide array of strategies to modulate and/or evade host immune and inflammatory responses $[13,15]$. A previous study using attenuated herpes simplex virus 1 mutant R7020, was capable of significantly reducing neointimal hyperplasia in New Zealand White rabbits receiving balloon angioplasty [16]. Myxoma virus, a poxvirus, encodes a viral anti-inflammatory protein called M-T7 [17]. This protein is capable of mimicking the IFN- $\gamma$ receptor and binds to a variety of human, rabbit and mouse C, C-C, and CXC chemokines [18]. A study using purified $\mathrm{M}-\mathrm{T} 7$ protein revealed reduced macrophage invasion due to the inhibition of chemokines in both rats and rabbits receiving vascular injury [15]. The myxoma virus also encodes a secretory serine protease inhibitor (termed Serp-1) that upon infection inhibits serine proteases such as plasminogen $[19,20]$. An earlier study [21] has demonstrated the effect of the Serp-1 glycoprotein on neointimal hyperplasia after balloon angioplasty in rabbits, showing a significant reduction in neointimal formation and macrophage invasion. A different myxoma virus protein called Serp-2 is a cross-class serpin that is present inside virus-infected cells. In rats, Serp-2 has been shown to significantly reduce plaque size at the site of angioplastic injury [22].

As an extension to the M-T7, Serp-1 and Serp-2 studies from myxoma virus, we decided to evaluate whether a systemic poxvirus infection could induce sufficient hostimmune modulation and/or suppression to elicit antiproliferative effects in a large animal model of restenosis. The porcine model was utilized due to the fact that the neointimal lesion that results after balloon-induced vascular injury is composed of smooth muscle and inflammatory cells, similar to that observed in human patients. Additionally, a species specific poxvirus is available to evaluate these observations. This was a critical issue as most of the known natural immunomodulators, including cytokines, are mainly species specific. This experimental model appears to be very useful in spite of the fact that neither swine cytokines nor swinepox virus (SPV) secretory proteins are well-characterized. In this report we demonstrate that the systemic poxvirus infection induces sufficient host immunosuppression and/or modulation to elicit an antiproliferative effect in a large animal model of neointimal hyperplasia.

\section{MATERIALS AND METHODOLOGY}

\section{Animals and Diet}

Female and male domestic feeder pigs (YorkshireHampshire-Landrace-Duroc crosses, 2-3 months old) were provided from Pharmacia \& Upjohn Farms and fed on S-985 chow ( $18 \%$ crude protein, Pharmacia \& Upjohn feed) until the PCI/POBA procedure. After PCI/ POBA, the animals were fed S-810-L chow (16\% crude protein, including 200 $\mathrm{gm} / \mathrm{ton}$ of the antibiotic lincomycin; Pharmacia \& Upjohn feed) throughout the rest of the study. The investigation conforms to the Guide for the Care and Use of the laboratory Animals published by the US National Institutes of Health.

\section{SPV Production and Infection Procedures}

SPV was obtained from American Type Culture Collection (VR-363, Rockville, Maryland) and cultivated in monolayers of Porcine Kidney 15 (PK-15) cells. PK-15 cells were grown in RPMI 1640 medium containing $10 \%(\mathrm{v} / \mathrm{v})$ newborn calf serum (NBCS), $2 \mathrm{mM}$ glutamine and antibiotics (100 units $/ \mathrm{ml}$ penicillin $\mathrm{G}$ sodium, $100 \mathrm{mg} / \mathrm{ml}$ streptomycin sulfate, and $0.25 \mathrm{mg} / \mathrm{ml}$ amphotericin B) (Growth Medium). Cells were cultured at $37^{\circ} \mathrm{C}$ in an incubator with $5 \% \mathrm{CO} 2$. Infected cells were harvested 7-8 days post-infection and the virus was concentrated and quantitated using established procedures for tanapox virus [23]. The concentrated virus was stored at $-70^{\circ} \mathrm{C}$. Mock infected cells were processed in an identical manner. One week prior to the angioplasty balloon (POBA) over-inflation procedure, $20.0 \mathrm{ml}$ venous blood sample was taken via superior vena cava venipuncture and the animals were segregated to separate holding rooms according to treatment to minimize the possibility of crossinfection. Animals were subsequently injected subcutaneously with either $1 \times 10^{8}$ plaque forming units (PFU) of SPV, or mock-infected cells in the right inguinal fold. A second blood sample was collected 3 weeks following balloon angioplasty. The serum collected was used to detect anti-SPV antibodies.

\section{Percutaneous Transluminal Coronary Balloon Angio- plasty (PCI/ POBA)}

All animal surgical protocols were performed according to local and national guidelines for animal care and were approved by the local IACUC animal committee (Pharmacia \& Upjohn) prior to the performance of the studies. The POBA procedure intentionally over-stretches a $2.0 \mathrm{~cm}$ segment of porcine left anterior descending (LAD) coronary artery and has been previously described in detail [24]. All 
POBA procedures were performed under general anesthetic with ketamine/midazolam (recommended dose per $\mathrm{kg}$ ) and the pigs were intubated for the procedure. Catheters were introduced via the right carotid artery exposed by cutdown and advanced retrograde to the left coronary ostium and then into the LAD. Immediately before coronary arterial advancement of a PCI catheter, a $50 \mathrm{mg}$ intravenous (i.v.) dose of the antifibrillatory, antiarrhythmic agent, bretylium tosylate was given and an intracoronary injection of nitroglycerin (50 to $150 \mu \mathrm{g}$ ) to alleviate post-PCI vasospasm. Heparin was also administered as a bolus of $200 \mathrm{U} / \mathrm{kg}$, i.v. followed by an i.v. infusion of $50 \mathrm{U} / \mathrm{kg} / \mathrm{hr}$. Aspirin was dissolved and administered i.v. at a dose of $5.0 \mathrm{mg} / \mathrm{kg}$. A GE-mobile X-ray (fluoroscope) connected to a video cassette recorder was used to locate the balloon visually and to record angiograms throughout the PCI procedure. After each procedure, these angiograms were replayed on a 12 inch monitor to calculate over-inflation ratio (OI ratio), which denoted the diameter ratio of the inflated balloon catheter ( 3.0 or $3.5 \mathrm{~mm}$ PCI catheter inflated with contrast dye) to the diameter ratio of the original coronary arterial site subjected to PCI. Throughout all PCI procedures, attempts were made to overstretch a $2.0 \mathrm{~cm}$ segment of LAD coronary artery between $30 \%$ and $50 \%$ (OI ratio $=1.3-1.5$ ). This level of overstretch has previously been shown to reproducibly elicit a neointimal proliferative response in the artery without causing thrombotic complications or vasospasm of the vessel [24]. Overstretch was applied twice in 60 second intervals with each inflation lasting 20 seconds at 8 atmospheres. After all surgical devices were removed and incision points surgically repaired, effectiveness of the POBA was confirmed by a repeat angiogram. At the end of the procedure, each pig was administered penicillin $G$ procaine intramuscularly (1.5 million units) and recovered in their cages over 2 to 3 hours post-procedure. Post-angioplasty treatment for 2 weeks consisted solely of daily aspirin at an oral dose of $80 \mathrm{mg} / \mathrm{kg}$.

\section{Histopathology and Morphometric Analysis of Porcine LAD Coronary Artery}

Two weeks following the $\mathrm{PCI} / \mathrm{POBA}$ procedure, pigs were anesthetized with ketamine/midazolam which was administered intramuscularly. The external jugular vein was surgically exposed to gain catheter access. Heparin (200 $\mathrm{U} / \mathrm{kg}$ ) was administered systemically followed by Evan's blue dye $(1 \% \mathrm{v} / \mathrm{v}$ in physiological saline) to delineate the lesion site at the LAD coronary artery. Evan's blue dye is excluded by intact endothelium indicative of the lesion site and thus was allowed to circulate in the pig for 1 hour prior to induction of euthanasia with Socumb $(>50 \mathrm{mg} / \mathrm{kg}$ sodium pentobarbital i.v.). Immediately after death, the hearts were removed and retrogradely perfused at $100 \mathrm{mmHg}$ with physiological saline for 15 minutes. The hearts were then perfused with Omni-fix II fixative (An-Con Genetics, Inc., Melville, NY) for 30 minutes. Three consecutive $1.0 \mathrm{~cm}$ LAD segments (two regions of altered Evan's blue dye uptake, 1 region of proximal or distal uninvolved coronary artery) were taken from each balloon injured site then fixed in Omni-Fix II fixative for more than 24 hours for subsequent paraffin embedding. Ten cross-sections were made throughout the entire length of each of the three sample segments. The sections were stained with aldehyde fuschin and counter stained with Van Giesson's solution to differentiate the internal elastic lamina (IEL). On the 30 cross-sectioned coronary arteries (20 sections from the Evan's blue stained $2.0 \mathrm{~cm}$ segment; 10 sections from the 1.0 $\mathrm{cm}$ segment showing no Evan's blue stain), morphometric measurements were performed with a computer aided image analysis system (The Microscope CO., Medina, OH). The degree of vascular injury induced by POBA balloon overinflation and the degree of neointimal hyperplasia was determined by previously established methods [24]. It has been previously demonstrated that the extent of IEL rupture corresponds directly with the magnitude of the neointimal hyperplastic response [24], therefore it was important to quantify both parameters in each cross-section. The extent of vessel injury was quantified as the injury index of each cross-section. This was calculated as the percentage of the internal elastic lamina that fractured due to balloon injury, divided by the entire circumference of the lamina. The resultant magnitude of the neointimal proliferative response was quantitated as the proliferation index, which was calculated as the ratio of the area of the neointimal lesion (NI) to the total area of the medial layer (M) for each crosssection. The values of the injury and proliferative indices from each cross-section taken from the sections of the same balloon-injured site were averaged to yield one value for each animal.

\section{RESULTS}

\section{Mortality and Exclusions}

Within a group of 22 pigs, 19 pigs survived the two week recovery period after POBA balloon-induced over-inflation. Two of the SPV infected pigs died from lethal arrhythmia due to acute POBA failure with arterial thrombotic occlusion. One control pig died from respiratory failure during post PCI recovery. From the 19 surviving pigs, 2 pigs (1 control and $1 \mathrm{SPV}$ infected) were excluded from analysis because they developed abnormal double-lumen morphology at the balloon-injured site. Also, one SPV infected pig was excluded from analysis due to an unusually large injury index In total, data from 8 control and 8 infected pigs were utilized to examine effects of SPV infection on restenosis.

\section{Symptomology in Swine}

Since poxviruses cause visible skin lesions on their hosts, symptoms on pigs were carefully examined for verification of SPV infection. Pigs infected with live SPV developed a lesion at the site of subcutaneous injection within one week post-infection. However, by three weeks post-infection, only 2 out of 8 SPV-infected pigs exhibited escalated skin lesions throughout the groin and the axillary regions (results not shown). It must be noted that 3 of the 8 mock-infected pigs developed rashes similar to SPV-infected pigs throughout their inguinal areas, suggesting the possibility of existing disease in the animal population (which is known to be endemic); or there could have been cross-contamination at the facility even though the groups were carefully segregated. Thus, the data was analyzed two ways. The first subset compared two groups: the 8 mock-infected control pigs and versus the $8 \mathrm{SPV}$-infected pigs. The second subset consisted of the 5 control pigs and 11 infected pigs. This subset accounts for an observation that 3 control pigs developed SPV-like symptoms 21 days post mock infection. 
The 3 pigs with SPV symptoms were transferred from control group to infected group.

\section{Morphometric Analysis of Swine LAD Coronary Arteries: Subset I}

In order to assess the effects of SPV infection on neointimal hyperplasia, cross-sections of balloon-injured porcine LAD coronary arteries were morphologically compared in mockinfected control pigs $(\mathrm{n}=8)$ vs SPV-infected animals $(\mathrm{n}=8)$ at 2 weeks post-balloon induced arterial injury. Table 1 subset I demonstrates that the acute magnitude of balloon-induced arterial overstretch (over-inflation ratio) was similar for both control and infected pigs at approximately $40 \%$ overstretch of the vessel. The injury index was found to be similar in both control and infected pigs as expected due to similar degrees of balloon over-inflation. However, the neointimal area, which develops at the internal elastic fracture site in the 2 week period following balloon-induced arterial injury, was $23 \%$ larger (but not statistically significant) in control pigs compared to infected pigs. The medial and external elastic lamina areas were similar indicating that the overall vessel sizes were similar in both groups of animals. To control for any possible differences in size of the vessels under study, the proliferation index was routinely calculated by the NI/M ratio mentioned earlier. In control pigs the NI/M ratio was 1.04 , which suggests that the neointima developed an area over a 2 week period roughly similar to that of the existing medial area of the vessel. However in SPV-infected pigs, the NI/M ratio was reduced to 0.85 which represents a $22 \%$ reduction ( $\mathrm{p}=0.08$, ANOVA).

A typical cross-section from a control mock-infected pig is shown in Fig. (1a). This animal had a NI/M ratio of 1.11 which was similar to the group mean of 1.04. Fig. (1b) represents a typical cross section from a SPV-infected pig with a NI/M ratio of 0.88 which was similar to the group mean of 0.85 . Note in both Fig. $(\mathbf{1 a}, \mathbf{b})$ that the neointimal area which develops as a consequence of balloon-induced overstretch of the vessel, occurs between the flaps of the ruptured internal elastic lamina.

\section{Subset II}

As indicated previously, 3 control pigs developed SPV symptoms as indicated by skin lesions in the inguinal areas. Thus, for analysis purposes, these 3 pigs were grouped with the previous $8 \mathrm{SPV}$ infected pigs and removed from the control group such that the control group presented now consisted of only 5 pigs and the SPV group consisted of 11 pigs. These data are demonstrated in Table 1, subset II. As seen previously in subset I, the degree of balloon overstretch and injury index is similar in both groups as indicated by similar over-inflation ratios of approximately $40 \%$ and injury indices of $25-26 \%$. However, the neointimal area is decreased by $27 \%$ in infected pigs compared to control animals. Furthermore, the medial and external elastic laminar areas are similar such that the NI/M ratio reflects a correspondingly statistically significant reduction of $33 \%$ $(\mathrm{p}=0.05)$.

\section{DISCUSSION}

Initiation of neointimal proliferation following PCI/ POBA involves activation of inflammatory and thrombotic cascades, which are commonly regulated by serine protease enzymes and inhibitors [8]. Inflammatory cascades result in the adhesion of leukocytes, induced by cytokine-leukocyte signaling. Many poxviruses encode proteins which inhibit or bind to host cytokines. Those proteins are known as immunomodulatory proteins. Myxoma virus produces serine protease inhibitors (Serp-1 and Serp-2) that upon infection inhibits serine proteases such as plasminogen and granzyme B $[19,20]$. Local introduction of purified immunomodulatory proteins encoded by vaccinia virus and myxoma virus has been reported to inhibit neointimal hyperplasia induced by vascular injury [21, 22]. In our study, based on the idea that all poxviruses secrete some sort of immunomodulatory polypeptides upon infection, an SPV systemic infection was assumed to secrete similar polypeptides. Since these SPV encoded polypeptides have not been characterized, we used systemic SPV infection on domestic feeder pigs to determine if SPV induced immunosuppression could cause an

Table 1. Morphological Analysis of Balloon-Injured Porcine Coronary Artery Segments Harvested 2 Weeks After Intentional PCI Over-Inflation

\begin{tabular}{|c|c|c|c|c|c|c|}
\hline \multicolumn{7}{|c|}{ Subset I } \\
\hline $\begin{array}{l}\text { Control (Mock } \\
\text { Infected) } n=8\end{array}$ & $1.43 \pm 0.01$ & $25.9 \pm 2.3$ & $0.49 \pm 0.07$ & $0.50 \pm 0.03$ & $2.82 \pm 0.14$ & $1.04 \pm 0.16$ \\
\hline SPV Infected $n=8$ & $1.41 \pm 0.02$ & $25.7 \pm 3.7$ & $0.40 \pm 0.04$ & $0.48 \pm 0.02$ & $2.80 \pm 0.10$ & $0.85 \pm 0.09$ \\
\hline Group & $\begin{array}{c}\text { Over -Inflation } \\
\text { Ratio }\end{array}$ & $\begin{array}{c}\text { Injury Index } \\
\left({ }^{1} \mathbf{I E L}_{\mathrm{f}} / \mathbf{I E L _ { \mathrm { c } }} \mathbf{x 1 0 0}\right)\end{array}$ & $\begin{array}{c}\text { Neointimal } \\
\text { Area(NI) }\left(\mathrm{mm}^{2}\right)\end{array}$ & $\begin{array}{c}\text { Medial Area (M) } \\
\left(\mathrm{mm}^{2}\right)\end{array}$ & $\begin{array}{c}{ }^{2} \text { EEL Area } \\
\left(\mathrm{mm}^{2}\right)\end{array}$ & $\begin{array}{c}\text { Proliferation Index } \\
\text { (NI/M) }\end{array}$ \\
\hline $\begin{array}{l}\text { Control (Mock } \\
\text { Infected) } n=5\end{array}$ & $1.42 \pm 0.02$ & $26.5 \pm 1.9$ & $0.52 \pm 0.03$ & $0.48 \pm 0.03$ & $2.74 \pm 0.20$ & $1.14 \pm 0.12$ \\
\hline
\end{tabular}

Internal Elastic Lamina (IEL $\mathrm{I}_{\mathrm{f}}=\mathrm{IEL}$ fracture length, $\mathrm{IEL}_{\mathrm{C}}=\mathrm{IEL}$ circumference).

${ }^{2}$ External Elastic Lamina.

${ }^{*} \mathrm{p}=0.05 v s$ control. 

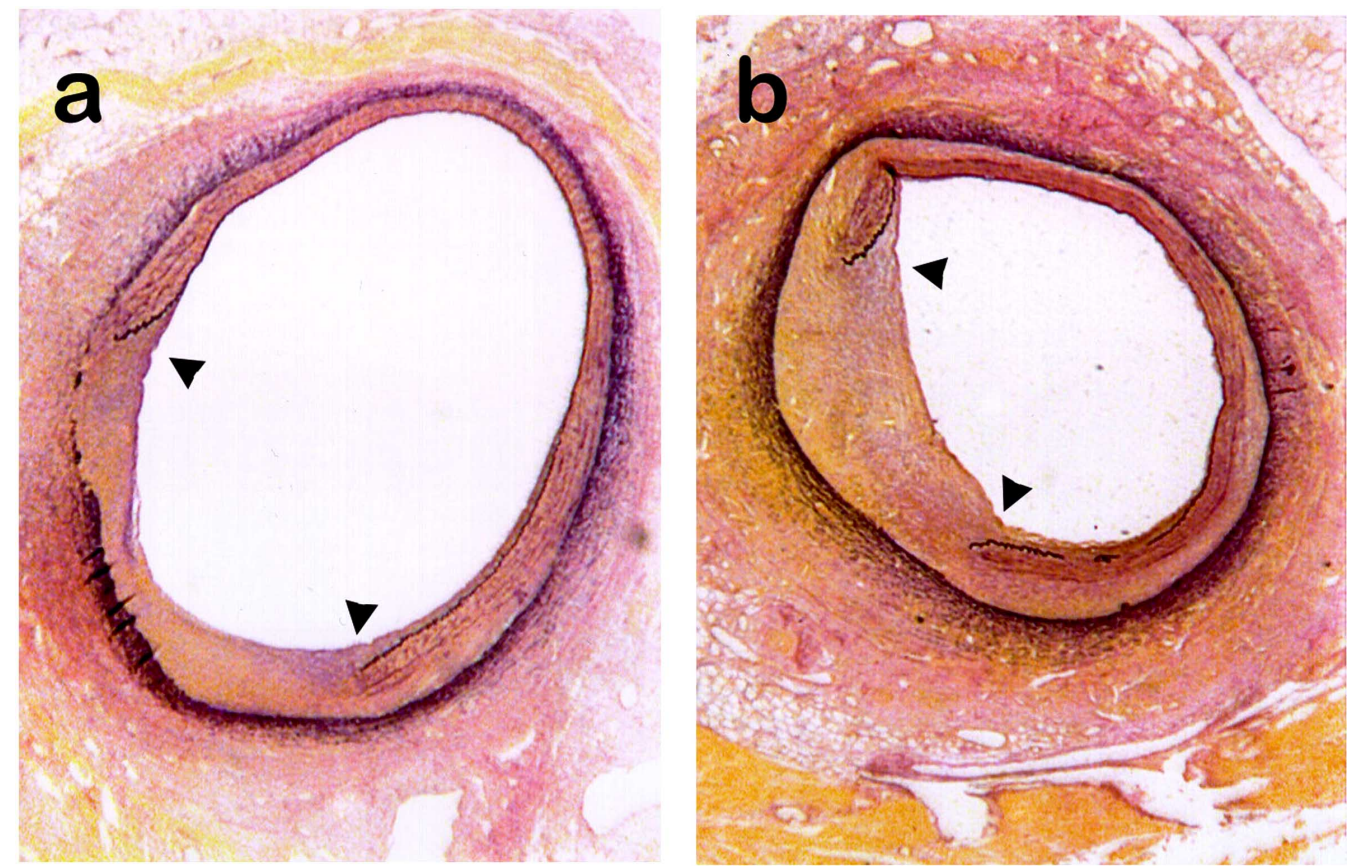

Fig. (1). Representative cross section of a LAD coronary artery from control/mock and SPV infected pigs. The arrowheads represent rupture sites made by the balloon over-inflation. These areas between arrowheads show neointimal cell proliferation, which is a main characteristic of the restenosis. Notice that degree of the neointimal cell proliferation in SPV-infected pig (a) differs from that of mock infected pigs (b). $\mathrm{NI} / \mathrm{M}$ of SPV infected pigs $=0.88, \mathrm{NI} / \mathrm{M}$ of mock infected pigs $=1.11$.

antiproliferative effect in a porcine model of injury-induced neointimal proliferation which mimics restenosis in humans.

In order to determine the degree of neointimal proliferation, at three weeks post-infection with either vehicle or SPV, pig LAD coronary arteries were harvested and morphologically examined. Subcutaneous administration of SPV to domestic feeder pigs a week prior to POBA balloon over-inflation reduced neointimal hyperplasia by $23 \%$ compared to mock-infected pigs. When the NI/M ratio was calculated, the magnitude of neointimal proliferation was $22 \%$ lower in the SPV-infected group compared to the mock-infected group (Table 1), however this data did not reach statistical significance.

As mentioned previously, 3 out of 8 control pigs developed skin rashes throughout the inguinal region, which resembled swinepox infection. Since swinepox is an endemic disease among swine populations, there is the possibility that those control pigs were cross contaminated or infected before the experiment. Thus, re-analysis of the data in which the 3 control pigs presenting with typical SPV-like infection are included in the SPV group. This generated a further reduction in the NI/M ratio for the SPV-infected pigs compared to control pigs, representing a 33\% reduction which reached statistical significance, despite the relatively small population sizes.

The unavailability of reproducible immunological techniques to demonstrate anti-SPV neutralizing antibodies and $\mathrm{T}$ cells severely restricted our ability to evaluate experimental SPV infections in pigs. It also restricted our ability to demonstrate whether some pigs were previously immune to SPV infections. Our efforts to establish a reproducible procedure to quantitate anti-SPV neutralizing antibodies were unsuccessful. These observations further confirmed earlier results from some leading SPV laboratories in the U.S. (Richard Moyer and Deoki Tripathy, personal communications). It is not clear if whether SPV itself or the pig immune system contributes to this limitation. However, we were able to confirm active SPV infection based on symptomology and anti-viral antibody detection in serum in all 11 pigs analyzed in subset II. Meanwhile, the 5 control pigs in subset II did not show any evidence of SPV infection using these techniques.

Like the myxoma virus serine protease inhibitor (serpin) Serp-2 that has been shown to reduce inflammatory cell invasion and plaque growth in rodent angioplastic injury models, SPV also encodes a similar serpin called SPV 145R or K1R $[22,25,26]$. The SPV145R has a high level of homology with the cowpox virus serpin/crmA homologue. The crmA protein from cowpox virus has been shown to inhibit the cellular IL-1 $\beta$ converting enzyme, modulating inflammation and apoptosis [27]. On a different note, the SPV 008 encodes a protein that shares $25 \%$ sequence homology the myxoma virus MT-7 protein [25]. The myxoma virus MT-7 protein is an IFN- $\gamma$ viroceptor and multiple chemokine binding protein, that has been shown to display anti-inflammatory properties in rat and rabbit vascular injury models $[15,17]$. In addition to the proteins mentioned here, SPV encodes many more immunomodulating proteins that could possibly control inflammation during a systemic infection and therefore reduce neointimal hyperplasia.

\section{CONCLUSION}

We have shown that a systemic infection of swinepox is capable of alleviating neointimal hyperplasia induced by angioplastic vascular injury. Although the actual proteins and mechanisms responsible for these observations are 
unknown, it suggests that a systemic infection of a poxvirus is capable of generating therapeutic effects for its host. Additional experiments knocking out selected SPV genes potentially involved in immunomodulation will precisely identify proteins which participate, either directly or indirectly, in the suppression of neointimal hyperplasia in pigs.

\section{CONFLICT OF INTEREST}

The authors confirm that this article content has no conflict of interest.

\section{ACKNOWLEDGEMENTS}

This work represents a portion of the Master's thesis of TS and was partially supported by an Upjohn grant to KE. We wish to thank Dr. Ronald Shebuski and Mr. William Humphrey for their technical advice and providing the facilities at Pharmacia \& Upjohn. We are grateful to Dr. Deoki Tripathy for his input on SPV replication and discussions on anti-SPV immunity. Drs. Robert Eversole and John Spitsbergen were kind enough to review the manuscript.

\section{REFERENCES}

[1] Schwartz RS, Holmes DR Jr, Topol EJ. The restenosis paradigm revisited: an alternative proposal for cellular mechanisms. J Am Coll Cardiol 1992; 20(5): 1284-93.

[2] Mitra AK, Agrawal DK. In stent restenosis: bane of the stent era. J Clin Pathol 2006; 59(3): 232-9.

[3] Williams DO, Holubkov R, Yeh W, et al. Percutaneous coronary intervention in the current era compared with 1985-1986: the National Heart, Lung, and Blood Institute Registries. Circulation 2000; 102(24): 2945-51.

[4] Htay T, Liu MW. Drug-eluting stent: a review and update. Vasc Health Risk Manag 2005; 1(4): 263-76.

[5] Farb A, Sangiorgi G, Carter AJ, et al. Pathology of acute and chronic coronary stenting in humans. Circulation 1999; 99(1): 4452 .

[6] Liu MW, Roubin GS, King SB 3rd. Restenosis after coronary angioplasty. Potential biologic determinants and role of intimal hyperplasia. Circulation 1989; 79(6): 1374-87.

[7] Hermans WR, Rensing BJ, Strauss BH, Serruys PW. Prevention of restenosis after percutaneous transluminal coronary angioplasty: the search for a "magic bullet". Am Heart J 1991; 122(1 Pt 1): 17187.

[8] Altieri DC. Proteases and protease receptors in modulation of leukocyte effector functions. J Leukoc Biol 1995; 58(2): 120-7.

[9] Carmeliet P, Moons L, Lijnen $\mathrm{R}$, et al. Inhibitory role of plasminogen activator inhibitor- 1 in arterial wound healing and neointima formation: a gene targeting and gene transfer study in mice. Circulation 1997; 96(9): 3180-91.
[10] Carmeliet P. Insights via t-PA and u-PA transgenic mice. Restenosis Summit VII 1995; 7: 250-3.

[11] Carmeliet P, Schoonjans L, Kieckens L, et al. Physiological consequences of loss of plasminogen activator gene function in mice. Nature 1994; 368(6470): 419-24.

[12] Jackson CL, Reidy MA. The role of plasminogen activation in smooth muscle cell migration after arterial injury. Ann N Y Acad Sci 1992; 667: 141-50.

[13] Cefai D, Simeoni E, Ludunge KM, et al. Multiply attenuated, selfinactivating lentiviral vectors efficiently transduce human coronary artery cells in vitro and rat arteries in vivo. $\mathrm{J}$ Mol Cell Cardiol 2005; 38(2): 333-44.

[14] Crook MF, Akyurek LM. Gene transfer strategies to inhibit neointima formation. Trends Cardiovasc Med 2003; 13(3): 102-6.

[15] Liu L, Lalani A, Dai E, et al. The viral anti-inflammatory chemokine-binding protein $\mathrm{M}-\mathrm{T} 7$ reduces intimal hyperplasia after vascular injury. J Clin Invest 2000; 105(11): 1613-21.

[16] Skelly CL, Chandiwal A, Vosicky JE, Weichselbaum RR, Roizman B. Attenuated herpes simplex virus 1 blocks arterial apoptosis and intimal hyperplasia induced by balloon angioplasty and reduced blood flow. Proc Natl Acad Sci USA 2007; 104(30): 12474-8.

[17] Upton C, Mossman K, McFadden G. Encoding of a homolog of the IFN-gamma receptor by myxoma virus. Science 1992; 258(5086): 1369-72.

[18] Lalani AS, McFadden G. Secreted poxvirus chemokine binding proteins. J Leukoc Biol 1997; 62(5): 570-6.

[19] Macen JL, Upton C, Nation N, McFadden G. SERP1, a serine proteinase inhibitor encoded by myxoma virus, is a secreted glycoprotein that interferes with inflammation. Virology 1993 195(2): 348-63.

[20] Upton C, Macen JL, Wishart DS, McFadden G. Myxoma virus and malignant rabbit fibroma virus encode a serpin-like protein important for virus virulence. Virology 1990; 179(2): 618-31.

[21] Lucas A, Liu L, Macen J, et al. Virus-encoded serine proteinase inhibitor SERP-1 inhibits atherosclerotic plaque development after balloon angioplasty. Circulation 1996; 94(11): 2890-900.

[22] Viswanathan K, Bot I, Liu L, et al. Viral cross-class serpin inhibits apoptosis, inflammation and atherosclerosis. In: Modulation of Atherothrombotic Factors: Novel Strategies for Plaque Stabilization. The Netherlands: Partners Ipstamp Enschede 2005.

[23] Essani K, Chalasani S, Eversole R, Beuving L, Birmingham L. Multiple anti-cytokine activities secreted from tanapox virusinfected cells. Microb Pathog 1994; 17(5): 347-53.

[24] Humphrey WR, Simmons CA, Toombs CF, Shebuski RJ. Induction of neointimal hyperplasia by coronary angioplasty balloon overinflation: comparison of feeder pigs to Yucatan minipigs. Am Heart J 1994; 127(1): 20-31.

[25] Afonso CL, Tulman ER, Lu Z, et al. The genome of swinepox virus. J Virol 2002; 76(2): 783-90.

[26] Massung RF, Jayarama V, Moyer RW. DNA sequence analysis of conserved and unique regions of swinepox virus: identification of genetic elements supporting phenotypic observations including a novel $G$ protein-coupled receptor homologue. Virology 1993; 197(2): 511-28.

[27] Ray CA, Black RA, Kronheim SR, et al. Viral inhibition of inflammation: cowpox virus encodes an inhibitor of the interleukin1 beta converting enzyme. Cell 1992; 69(4): 597-604. 